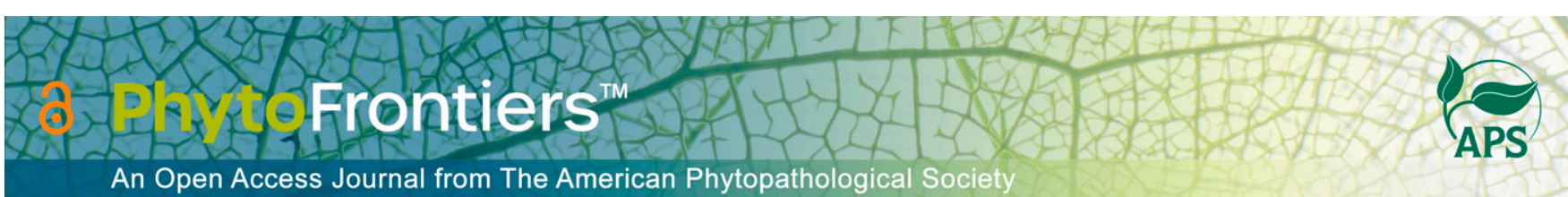

\title{
Research
}

\section{Field Evaluation of Interactions Between Insects and Erwinia amylovora in a New York Apple Orchard}

\author{
Matthew Boucher ${ }^{1,+}$ (i) | Rowan Collins ${ }^{1} \mid$ Kayli Harling $^{1} \mid$ Gabrielle Brind'Amour $^{1} \mid$ Stephen Hesler ${ }^{1}$ | \\ Karen Wentworth ${ }^{1}$ | Kerik Cox $^{2}$ | Greg Loeb ${ }^{1}$ |
}

${ }^{1}$ Department of Entomology, Cornell AgriTech, New York State Agricultural Experiment Station, Cornell University, Geneva, NY 14456

2 Section of Plant Pathology \& Plant Microbe Biology, School of Integrated Plant Sciences, Cornell AgriTech, New York State Agricultura Experiment Station, Geneva, NY 14456

† Corresponding author: M. T. Boucher; mzb6294@ psu.edu

Accepted for publication 25 January 2021.

\section{Funding}

Support for this research was provided by the National Science Foundation Graduate Research Fellowships Program grant number DGE-1650441, Northeast SARE Graduate Student Grant number GNE16-115-29994, New York State Department of Agriculture and Markets Apple Research

Development Program number C200849, Federal Capacity Funds number 2016-17-199, Grace Griswold Endowment, and Arthur Boller Research Fund.

The author(s) declare no conflict of interest.

$\boldsymbol{e}$-Xtra: Supplementary materials are available online.

\begin{abstract}
The role of insects in dissemination of Enwinia amylovora has been studied for over 100 years. Pollinating bees do not feed on bacterial ooze but are suggested to transmit between flowers. It has been suggested that various hemipteran species walk on bacterial ooze and subsequently shed acquired bacteria into their own feeding wounds. Dipterans have been observed readily feeding on ooze, but their importance has been understudied. The goal of this study was to advance understanding of the ecology of insect-mediated transmission of $E$. amylovora through field collections and observations conducted in a research apple orchard with actively oozing fire blight symptoms. We found that field-collected pollinating bees did not test positive for the bacterium, suggesting that their role in blossom blight dissemination may be overstated. Flies were prominent flower visitors, underscoring the need for further research into their role in bloom time bacterial dissemination. Flies were observed feeding on ooze droplets in the late spring and early summer and the insects retained bacteria for at least 7 days. Flies shed transmissible amounts of $E$. amylovora for the duration of the experiment. The role of hemipterans was not clarified in this study but it is possible that their role is indirect through interactions with other insects. Collectively, this research outlines the ecological role of different insects in disease transmission and underscores the underappreciated potential importance of flies, providing a roadmap toward a better understanding of the complex dynamics at play.
\end{abstract}

Keywords: blossom blight, Diptera, Erwinia amylovora, exopolysaccharide, fire blight, Hemiptera, Hymenoptera, pollinators, ooze

Fire blight is a bacterial disease of pomaceous fruit, primarily apple and pear, caused by the bacterium Erwinia amylovora (van der Zwet et al. 2012a). The bacterium can infect any plant tissue if a point of entry (a wound or natural opening) is available. Fire blight symptoms include wilting of succulent shoots, necrosis of blossoms and fruit, 
development of cankers on woody tissue, and the presence of bacterial ooze (Oh and Beer 2005). Bacterial ooze consists of $E$. amylovora encased in exopolysaccharides, which accumulates in the parenchyma and ultimately ruptures the epidermis, allowing ooze to exude from the injury (Slack et al. 2017). Ooze ranges in color from opaque to red and serves as primary inoculum in the spring, when it emerges from the margins of overwintering cankers (van der Zwet et al. 2012a), and as secondary inoculum in the summer, when it emerges from succulent shoots (Slack et al. 2017). The minimum infective dose of E. amylovora is dependent on high water availability, ideal temperatures $\left(21\right.$ to $\left.27^{\circ} \mathrm{C}\right)$, available points of entry, and plant tissue age but has been estimated to require epiphytic populations as low as $1 \times 10^{2} \mathrm{CFU} /$ $\mathrm{ml}$ (Crosse 1972; Farkas et al. 2012; Thomson 1986; van der Zwet and Keil 1979). In contrast, E. amylovora populations in individual ooze droplets often exceed $1 \times 10^{6}$ CFU (Slack et al. 2017). Insect activity is an important mode of mechanical dissemination for this bacterium but interactions pertinent to insect-mediated dissemination, especially those involving flies (Diptera), pollinating bees (Hymenoptera), and sap feeders (Hemiptera), remain poorly described (van der Zwet et al. 2012b).

Flies were anecdotally implicated in E. amylovora transmission in the early 1900 s but researchers failed to demonstrate transmission by various species (Stewart and Leonard 1916). This study concluded that flies could not generate points of entry for E. amylovora but hypothesized that contaminated flies could deliver bacteria to blossoms or to wounds created by sap feeders such as Lygus lineolaris (Stewart and Leonard 1916). Indeed, flies exposed to oozing cankers and then caged to blossom clusters resulted in 2 to $4 \%$ of blossoms becoming symptomatic (Parker 1936). A separate study demonstrated that flies were abundant in diseased orchards and that $56 \%$ of flies surveyed were positive for E. amylovora (Miller 1972). Bacterial loads in these flies ranged from $1 \times 10^{1}$ to $1 \times 10^{5} \mathrm{CFU} /$ insect (Miller 1972), and recent studies reported similar CFU ranges for flies under laboratory settings (Boucher et al. 2019; Ordax et al. 2015). E. amylovora survived on the surface of the Mediterranean fruit fly, Ceratitis capitata, for as long as 28 days and in the gut for as long as 8 days, demonstrating $E$. amylovora survival in fly viscera for the first time and, thus, the potential to continuously initiate new infections (Ordax et al. 2015).

Pollinating insects such as honeybees have also been implicated in the spread of fire blight (van der Zwet et al. 2012b). Honeybees do not visit oozing cankers (Parker 1936) but have primarily been shown to transmit E. amylovora from blossom to blossom (Parker 1936; Pierstorff and Lamb 1934). Honeybees caged with a tree containing 19 artificially inoculated blossoms resulted in $67 \%$ of originally healthy blossoms becoming symptomatic, while honeybees caged to control trees without inoculated blossoms resulted in no symptomatic blossoms (Pierstorff and Lamb 1934). Another experiment demonstrated that bees transmitted E. amylovora to $52 \%$ of healthy blossoms when confined with one diseased dwarf tree and two healthy dwarf trees (Keitt 1941). The same study argued that nectar concentration limited honeybee transmission efficiency because healthy flowers that had medium and high nectar concentrations did not develop fire blight symptoms when visited by contaminated bees (Keitt 1941).

Sap feeders such as leafhoppers and plant bugs have received attention as potential vectors but their role in transmission varies (van der Zwet et al. 2012b). Stewart (1913) caged tarnished plant bugs, L. lineolaris, to healthy pear shoots smeared with cultured E. amylovora, resulting in approximately $70 \%$ of shoots exhibiting fire blight symptoms. This led the author to hypothesize that (i) feeding wounds doubled as points of entry for E. amylovora, (ii) insects acquired bacteria by walking across oozing cankers, and (iii) bacteria were mechanically transmitted to feeding wounds on succulent shoots (Stewart 1913). Later work showed that contaminated L. lineolaris could initiate infections in an average of $24 \%$ of pear fruit they were exposed to (Stahl and Luepschen 1977). Studies on potato leafhopper (Empoasca fabae) suggested that insecticides to control for the pest significantly reduced fire blight incidence (Leahy et al. 2006; Pfeiffer et al. 1999), leading to the hypothesis that leafhoppers facilitate translocation of epiphytic Erwinia amylovora into the plant (Leahy et al. 2006); however, no follow-up research was published. Molecular studies on transmission of E. amylovora by Aphis pomi showed that $0 \%$ of 200 aphids exposed to E. amylovora could initiate an infection in apple shoots, likely because they could not egest enough bacteria to overcome plant defenses (Plurad et al. 1967). Overall, sap feeder wounds are commonly hypothesized points of entry for E. amylovora but the relevance of these wounds to fire blight outbreaks is tenuous and has only been studied indirectly (Leahy et al. 2006; Plurad et al. 1967; Stewart 1913).

The goal of this study was to define and quantify interactions between insects and infested plants to better understand the relative importance of potential vectors. In 2016 and 2017, we conducted a survey of three commonly invoked mechanical vectors (pollinating bees, flies, and sap feeders) from the start of bloom through the end of the growing season to (i) establish the frequency of E. amylovora infested insects and (ii) identify intervals during which insect activity may have a significant impact on disease spread. In this survey, we did not detect E. amylovora on any pollinator and hypothesized that pollinators may be avoiding infested flowers (Cellini et al. 2019). Based on this result, we compared the overall prevalence of infested flowers in the orchard to the prevalence of infested flowers visited by pollinators in 2018 to (i) assess potential avoidance behavior and (ii) quantify the frequency of pollinator visits to infested flowers. Additionally, we regularly observed flies feeding on ooze throughout data collection in our initial survey and sought to quantify this interaction in 2018. Specifically, we observed the length of ooze feeding bouts, subsequent persistence of E. amylovora on or in flies, and the frequency of fly visits to different symptomatic tissue types and ooze colors.

\section{MATERIALS AND METHODS}

\section{Field site}

All surveys were conducted in a 0.7-ha experimental research orchard at Cornell AgriTech in Geneva, NY (42 $52^{\prime} 23.2^{\prime \prime} \mathrm{N}$, $\left.77^{\circ} 01^{\prime} 40.1^{\prime \prime} \mathrm{W}\right)$. The orchard was planted in 2012 in an open field surrounded by research plots that varied in crops produced from year to year and included grains, beet, bean, and cabbage. No other fire-blight-susceptible crop was grown within $160 \mathrm{~m}$. The original design of the orchard consisted of four independent sections of 50 trees each (Malus domestica 'Idared' on B.9 rootstock), with sections spaced approximately $6 \mathrm{~m}$ apart and separated by a strip of grass that was mowed biweekly. Each section was treated as an independent block and consisted of five rows of 10 trees, arranged in a grid; each tree was within-row spaced approximately $3.5 \mathrm{~m}$ apart, with approximately $5 \mathrm{~m}$ between rows. Rows were planted in bare strips $2.5 \mathrm{~m}$ wide and $44 \mathrm{~m}$ long and each bare strip within a block was separated by 2-mwide grass strips. Grass strips were mowed biweekly, and bare strips were treated with pre- and postemergent herbicides biweekly to control for flowering weeds. The orchard was managed according to a standard commercial chemical management program, excluding fire blight management, and trees were pruned in August and over the winter in each year (Agnello et al. 2019). 
Trees contained approximately 100 blossom clusters each and live trees were of similar size and flower density from year to year. In 2015, the orchard was experimentally inoculated with E. amylovora strain Ea273 (ATCC 49946) (Sebaihia et al. 2010).

Active fire blight was present throughout the study and tree mortality reached an apparent $72 \%$ by the end of 2015 . Dead trees were left in the orchard, and block structure was not altered due to 2015 tree mortality. However, many of the trees recorded as dead in 2015 produced new shoots in 2016 and tree mortality was not recorded in 2016, though only a few trees recovered after 2016. By the end of 2017 , greater than $80 \%$ of trees were killed by fire blight and sampling in 2018 was restricted to the remaining live trees that maintained bloom densities approximating 2016 and 2017 densities ( 21 trees dispersed across blocks, amounting to approximately $10 \%$ of the original orchard). Additional measures of fire blight severity in this orchard from 2015 to 2018 are available in Supplementary Table S1. A summary of environmental conditions for each study year is available in Supplementary Table S2. Environmental data were aggregated from a weather station located on site using the Network for Environment and Weather Applications (Carroll et al. 2017).

\section{Pollinator survey}

Starting in late April, we monitored flower development daily until king flowers (the central bud that is first to open in a given cluster of buds) began to bloom. In 2016, the first king blossoms were observed on approximately 9 May and full bloom was reached by 16 May; 97 base $4^{\circ} \mathrm{C}$ degree days (DD) accumulated during this time. The orchard reached $80 \%$ petal fall by 20 May and 64DD accumulated between full bloom and $80 \%$ petal fall. Pollinators were sampled between 9 and 12 May, and then again from 18 to 20 May. Between the first day of sampling (9 May) and the last day of sampling (20 May), 153DD accumulated. In 2017 , the first open king blossoms were observed on approximately 3 May but consistent temperatures below $15^{\circ} \mathrm{C}$ between 3 and 9 May delayed bloom progression and pollinator activity. Only 38DD accumulated during this time. The orchard reached full bloom by 11 May and $80 \%$ petal fall by 17 May, during which 108DD accumulated. Between 9 and 19 May (the final day of sampling), 171DD accumulated. In 2018, the first open king blossoms were observed on 14 May and full bloom was reached on approximately 17 May. By 21 May, the orchard reached $80 \%$ petal fall, and approximately 167DD had accumulated between 14 and 21 May. From the start of sampling (17 May) to $80 \%$ petal fall (21 May), 101DD accumulated. An additional 109DD accumulated between 22 May and the last day of sampling on 25 May for a total accumulation of 276DD during bloom. Two to three observers each walked individual orchard blocks for $30 \mathrm{~min}$ to an hour between 10 A.M. and noon and captured bees that landed on flowers in 50-ml conical tubes. Captures were incidental, such that observers visited every flowering tree in their assigned block two times and caught flower visitors when they were observed. In 2016 and 2017, we only captured bees that visited flowers. In 2018, bees and flies that visited flowers were captured. Insect preferences for flowers based on phenology were not considered in this survey. Pollinators were put on ice and returned to the lab to be identified and assessed for E. amylovora.

\section{Sticky card survey}

Yellow-sticky-card surveys were conducted for 20 weeks in 2016 and 18 weeks in 2017 starting in the first week of May in each year and lasting until mid- to late August. Each week, we used the RANDOM function in Microsoft Excel to select five trees from each orchard block and deployed two 7.6-by-12.7-cm yellow sticky cards (Olson Products, Inc., Medina, OH, U.S.A.) in each tree for a total of 40 cards/week. Cards were deployed in trees regardless of health status, with one card deployed at knee level around the trunk and the other at shoulder or eye level in the canopy. Cards were removed weekly, placed into clear plastic sandwich bags, and returned to the lab where insects were identified and assessed for E. amylovora.

\section{Insect identification}

Samples were identified to genus or species under a dissecting microscope based on morphology. Three individuals sorted all samples, working simultaneously and cross-checking identifications haphazardly. For pollinator surveys in 2016 and 2017, only Apis mellifera was identified to species; all other bees were identified to genus. In the 2018 pollinator survey, insects were cataloged as honey bee, large bee, medium bee, small bee, or fly. Honey bees ( $A$. mellifera) and flies (Diptera) were sight identified, large bees were as big as honey bees or bigger, medium bees were approximately the size of Andrena miserables, and small bees were approximately the size of Lasioglossum spp. In the 2016 sticky card survey, only sap feeders in high abundance (Empoasca fabae Harris, Macrosteles quadrilineatus Forbes, Paraphlepsius spp., and Philaenus spumarius Linnaeus) were identified and tested. In 2017, sap feeders and flies in high abundance (Delia spp. and miscellaneous) were identified and tested. Flies were added in 2017 due to (i) their prevalence on sticky cards in 2016, (ii) observations of various dipterans feeding on ooze while collecting samples in 2016, and (iii) feedback from growers. Sap feeders that did not test positive in 2016 were not identified or tested in 2017, and abundances of $P$. spumarius were too low to sample in 2017.

\section{8 blossom visitation survey}

On 6 days spanning from 17 to 25 May 2018, observation teams sampled flowers visited by insects for Erwinia amylovora in the research orchard. One observation constituted the first three flowers visited by a single insect (recorded as honeybee, small bee, medium bee, large bee, or fly). Each time an insect landed on a flower, it was timed for the duration of its visit, if it approached the blossom from the top (landing on anthers) or side (landing on petals), and if it fed on nectar (whether its proboscis extended into the floral cup). Each visited flower was then collected into a 2-ml tube and stored on ice. Teams collected five observations per tree and sampled one to two trees per sampling day. For every tree observed, 10 flowers were arbitrarily collected immediately prior to insect observation to establish the overall prevalence of the pathogen on flowers (control flowers). If an individual tree was sampled on multiple days, control flowers were collected on each day.

Samples were returned to the lab and processed the same day they were collected. The stigma, anthers, and hypanthium of each flower were shredded with a small pair of scissors. Scissors were sterilized for $30 \mathrm{~s}$ in $95 \%$ ethanol and flamed before use on a new flower. Shredded flowers were pulverized in a 1.5-ml Eppendorf tube by hand using a plastic pestle; soaked in $1 \mathrm{ml}$ of autoclaved, distilled water for $1 \mathrm{~h}$; and assessed for E. amylovora. Differences in CFU counts on flowers visited by insects and control flowers were analyzed in $\mathrm{R}$ using a generalized linear mixed-effects model with the glmmTMB library and compared using the emmeans library (Brooks et al. 2017; Lenth 2020; R Core Team 2019). A negative binomial distribution was used due to overdispersion of the counts, and flower source (insect visited or 
control) was a fixed effect while block and tree were included as random effects.

\section{Ooze location and color survey}

On three occasions in June 2018, the location and color of $E$. amylovora ooze droplets detected in the research orchard were recorded. We counted 100 droplets on each occasion, and 20 to 25 droplets were haphazardly sampled per tree, with a total of 14 trees surveyed. Separate sets of trees were used in each of the three samplings to ensure that no droplet was double counted. Ooze droplet color was recorded as white, red, orange, or yellow (Slack et al. 2017). Location was recorded as shoot, leaf (any leaf tissue including petiole), fruit, or woody tissue (any lignified part of the tree at the time of study).

\section{Fly feeding and E. amylovora persistence}

On 10 days with temperatures between $60^{\circ} \mathrm{F}\left(16^{\circ} \mathrm{C}\right)$ and $85^{\circ} \mathrm{F}$ $\left(29^{\circ} \mathrm{C}\right)$ from 1 to 21 June 2018 , observers located oozing trees and waited for dipterans to land on heavily infected trees in the research orchard. This temperature range was chosen because it is the range at which common flies in the orchard are most active (Miller and McClanahan 1960). Insects that approached or encountered ooze droplets were timed for the duration of feeding on the droplet. Feeding initiated when the proboscis extended to the surface of the droplet and ended when the proboscis retracted. Observations were made with the naked eye. When feeding terminated, we attempted to capture each fly in a 15-ml conical tube while they remained on the shoot. Tubes were brought close to the insect from behind and placed above them, with a gloved hand underneath the shoot to encourage the insect to fly into the tube. Location and color of droplets that were fed on were recorded, and droplets were only observed once. Additionally, only one droplet per shoot was observed even if multiple droplets were present on the shoot. Color and location of droplets visited by flies were compared with observed droplet color and location distributions in $\mathrm{R}$ using a $\chi^{2}$ goodness of fit test ( $\mathrm{R}$ Core Team 2019).

Captured flies were returned to the lab, identified as either Delia spp. or miscellaneous, and used to evaluate persistence of E. amylovora on or in the insect. Each fly was transferred to a new $15-\mathrm{ml}$ conical tube with a 1-by-1-cm square of paper towel soaked in 5\% sucrose, and every day for 7 days each fly was transferred to a new, identical tube. The paper towel was removed from the old tube, and $1 \mathrm{ml}$ of autoclaved, distilled water was added to the tube. Tubes were vigorously shaken by hand to wash the tube and the mixture was assessed for E. amylovora using the plating method described below.

\section{Assessment for E. amylovora}

After identification, insects were transferred into a tube containing 500 to $1,000 \mu \mathrm{l}$ of autoclaved distilled water, depending on insect size. For sticky cards, insects were removed from cards by cutting away the plastic surrounding the insect, then adding a small drop of Goo Gone liquid degreaser (Weiman Products, Gurnee, IL, U.S.A.) to the sample (Cieniewicz et al. 2018). After 10 to $30 \mathrm{~s}$, insects were removed from the card without damaging them and transferred into tubes. Samples were either hand homogenized with a plastic pestle (in 2016 and 2018) or mechanically homogenized with a mixer mill (model MM400; Retsch, Haan, Germany) for 2 min at $25 \mathrm{~Hz}$ (in 2017). In 2016, pollinator and sticky card samples were pooled by combining 10 $\mu l$ of 10 individual samples from the same species into one
Eppendorf tube, and pooled samples were subject to DNA extraction with DNAzol (catalog number 10503027; Thermo Fisher, Waltham, MA, U.S.A.) using the manufacturer's protocol (Broadley et al. 2017). In 2016, if we detected E. amylovora in a pool, then the 10 individuals comprising the pool were tested individually to acquire a count of samples containing detectable levels of E. amylovora.

In 2017, DNA extractions were conducted on individual samples using a lysis buffer $(50 \mathrm{mM} \mathrm{KCl}, 10 \mathrm{mM}$ Tris- $\mathrm{HCl}[\mathrm{pH}$ 8.3], $2.5 \mathrm{mM} \mathrm{MgCl} 2,0.45 \%$ Triton $\times 100,0.45 \%$ Tween 20 , $0.01 \%$ gelatin, and Proteinase $\mathrm{K}$ at $60 \mu \mathrm{g} / \mathrm{ml}$ ) (Li et al. 2014). DNA extraction followed $\mathrm{Li}$ et al. (2014), in which a 1:1 ratio of lysis buffer and homogenized sample was added to a $0.2-\mathrm{ml} \mathrm{PCR}$ tube, centrifuged for $30 \mathrm{~s}$ at $10,000 \mathrm{rpm}$, and stored at $-80^{\circ} \mathrm{C}$ for 1 h. Next, samples were incubated in a thermocycler at $60^{\circ} \mathrm{C}$ for 1 $\mathrm{h}$, then at $95^{\circ} \mathrm{C}$ to deactivate the Proteinase $\mathrm{K}$, and stored at $-20^{\circ} \mathrm{C}$ until use in PCR assays ( $\mathrm{Li}$ et al. 2014). DNA extraction protocols in 2016 and 2017 were compared side by side to ensure that results were similar before switching to the new method.

In both 2016 and 2017, samples were tested for the presence of the pEA29 plasmid using PCR (Tancos et al. 2016). PCR assays were conducted using EmeraldAmp Max PCR Master Mix (catalog number RR320; Takara Bio USA, Inc., Mountain View, CA, U.S.A.) and primers AJ75/76 (McManus and Jones 1995). Individual reactions contained $12.5 \mu \mathrm{l}$ of master mix, $9 \mu \mathrm{l}$ of distilled $\mathrm{H}_{2} \mathrm{O}, 0.5 \mu \mathrm{l}$ each of forward and reverse primers, and 2.5 $\mu 1$ of DNA template. Thermal cycler (catalog number 170-9703; Bio-Rad Laboratories, Inc., Hercules, CA, U.S.A.) conditions matched those used by Tancos et al. (2016) and PCR products were run on a $1 \%$ agarose gel in $1 \times$ Tris-acetate-EDTA buffer and stained with SYBR Safe DNA Gel Stain (catalog number S33102; Thermo Fisher) at $90 \mathrm{~V}$ for $45 \mathrm{~min}$. Gels were imaged with a KODAK Gel Logic 200 System (KODAK, Rochester, NY, U.S.A.).

In 2018, insect, flower, and persistence samples assessed for $E$. amylovora were serially diluted and plated on Crosse-Goodman media, a selective media on which E. amylovora colonies exhibit a characteristic cratering pattern (Crosse and Goodman 1973). Plates were sealed with Parafilm and incubated at $28^{\circ} \mathrm{C}$ for approximately 60 h. After incubation, positive samples were identified and $E$. amylovora CFUs were counted under $\times 30$ magnification. The detection threshold of this assay was $200 \mathrm{CFU} / \mathrm{ml}$. Positive tests were spot checked by growing bacteria overnight in Luria-Bertani broth (catalog number 12795-027; Invitrogen, Carlsbad, CA, U.S.A.) at $28^{\circ} \mathrm{C}$; then, $500 \mu \mathrm{l}$ of the resulting suspension was inoculated into immature Gala apple fruit. Immature fruit were incubated at $28^{\circ} \mathrm{C}$ and $>95 \%$ relative humidity for 7 to 14 days until ooze began to exude from the fruit surface. Dilutions were plated on Crosse-Goodman media and incubated and evaluated as described above (Crosse and Goodman 1973).

\section{RESULTS}

\section{Pollinator and sticky card survey: 2016 and 2017}

No pollinating bees tested positive in 2016 or 2017 out of a total of 749 individual pollinators captured, representing a diversity of blossom visitors (Table 1 ). In sticky card surveys, $E$. amylovora was detected in two hemipteran species, one hemipteran genus, and one dipteran genus (Table 2). Meadow spittlebug ( $P$. spumarius) tested positive in 2016 but no samples of this insect were collected in 2017. Delia spp. constituted a mix of Delia platura and D. florilega samples, and Delia spp. were the predominant dipteran captured in the field in both 2016 and 2017 (Fig. 1). In 2016, the population of Delia spp. on yellow sticky 
cards was relatively stable across the growing season. Numbers captured were higher in 2017 compared with 2016, peaking in June and July before declining to numbers comparable with 2016. In 2017, Delia spp. accounted for 15 of 24 positive samples (63\%). Overall, Delia spp. tested positive for E. amylovora less than $1 \%$ of the time and no other dipteran tested positive (Table 2). In all, 45 (68\%) of the 66 sticky card samples that we detected E. amylovora on were collected in June and July (Table 3).

\section{Ooze location and color survey}

The distribution of ooze droplet colors observed in the field and the distribution of ooze droplet colors visited by flies was determined (Fig. 2). Orange and yellow droplets were the most prevalent in the orchard and the most often visited by flies. There were no significant differences in the distribution between observed droplet color and color visited by flies $\left(\chi^{2}=2.5898, P=\right.$ $0.4503)$. The distribution of ooze droplet location on the tree and the location of ooze droplets visited by flies was also determined (Fig. 3). Ooze droplets were found on green succulent shoots most often $(75 \%)$ and flies visited droplets on shoots approximately $67 \%$ of the time. There was a significant difference between observed droplet location and location of ooze visited by flies $\left(\chi^{2}=55.129, P=0.0005\right)$, indicating that flies visited ooze more frequently on fruit and less frequently on woody tissue then would be expected based on the observed distribution of ooze.

\section{Fly feeding and persistence assay}

In total, 30 observations of flies feeding on ooze were recorded (Table 4). Delia spp. accounted for approximately $58 \%$ of flies

\section{TABLE 1}

Breakdown of pollinating bees collected in 2016 and 2017 by insect genus

\begin{tabular}{lcrr}
\hline Genus & Common name & 2016 & 2017 \\
\hline Apis & Honey bees & 62 & 66 \\
Bombus & Bumble bees & 0 & 2 \\
Xylocopa & Carpenter bees & 0 & 9 \\
Andrena & Mining bees & 98 & 164 \\
Lasioglosssum & Sweat bees & 241 & 47 \\
Halictus & Sweat bees & 12 & 5 \\
Osmia & Mason bees & 0 & 3 \\
Augochlorella & Sweat bees & 1 & 19 \\
Augochlora & Sweat bees & 2 & 0 \\
\hline
\end{tabular}

observed, with individuals from the Muscidae and Sarcophagidae families making up the remaining $42 \%$. Feeding times on ooze ranged widely, from short bouts of $2 \mathrm{~s}$ to bouts exceeding $6 \mathrm{~min}$. The mean feeding time was close to 3 min for Delia spp. and approximately 2 min for other dipterans. Of the 30 dipterans recorded, 16 were captured and tested for E. amylovora daily for 7 days. Ten of these flies contained E. amylovora (Table 5). Insects ranged in E. amylovora infestation from 1 to 7 days and only 1 of 10 samples contained the pathogen for all 7 days. $E$. amylovora populations over time are presented in Figure 4.

\section{Blossom visitation survey}

We observed insect visitation and sampled flowers from 21 trees. In the first 4 days of sampling, only 1 of 21 trees contained infested flowers. By petal fall, 4 of 21 trees (19\%) contained infested flowers. Flies were the most frequent flower visitors, constituting 54\% (90 of 167) of all visitors observed (Table 5). In total, $39 \%$ of observed insect visits occurred in the first 2 days of sampling, $48 \%$ of observed visits occurred in the middle 2 days of sampling, and $12 \%$ of observed visits occurred in the final 2 days of sampling. Honeybees and large bees spent the least amount of time interacting with each flower visited, while medium bees, small bees, and flies spent nearly $20 \mathrm{~s}$ longer on average interacting with flowers (Table 5). Bees landed on flower anthers (approach from top) greater than 50\% of the time, while flies were more likely to land on the petals (approach from side) (Table 5). Additional visitation and behavioral data are summarized in Table 5.

Only 12 of 261 (5\%) flowers visited by insects were infested with E. amylovora compared with 36 of 315 (11\%) control flowers. In all, 11 of 12 infested flowers visited by insects were collected from one tree and 27 of 36 infested control flowers were collected from the same tree (Table 6). Of the infested flowers visited by insects, 8 of 12 were visited by flies (Table 5). Bacterial populations in infested control flowers were significantly higher than bacterial populations in insect-visited flowers ( $t$ ratio $=-2.259, P=0.03$ ) (Fig. 5). Bacterial populations in infested flowers increased as bloom progressed, with mean populations in flowers reaching $1.2 \log _{10} \mathrm{CFU} / \mathrm{ml}$ in the first 2 days of sampling, before jumping to a mean of $3.5 \log _{10} \mathrm{CFU} /$ $\mathrm{ml}$ thereafter. We collected 121 insects (20 Apis mellifera, 60 wild bees, and 41 flies) from 38 blooming trees for E. amylovora assessment. In total, 30 of 121 insects were collected from trees known to contain the pathogen based on concurrent detection of E. amylovora on flowers collected from those trees. None of the 121 insect samples (0\%) contained E. amylovora.

\begin{tabular}{|c|c|c|c|c|c|c|c|}
\hline \multicolumn{8}{|c|}{ TABLE 2} \\
\hline \multicolumn{8}{|c|}{ Results of PCR detection of Erwinia amylovora for pollinator and yellow sticky card surveys in 2016 and $2017^{\mathrm{a}}$} \\
\hline \multirow[b]{2}{*}{ Order } & \multirow[b]{2}{*}{ Insect, group } & \multicolumn{3}{|c|}{2016} & \multicolumn{3}{|c|}{2017} \\
\hline & & Collected & $\operatorname{Pos}(n)$ & Pos $(\%)$ & Collected & Pos $(n)$ & Pos $(\%)$ \\
\hline \multirow[t]{2}{*}{ Hymenoptera } & Apis mellifera & 62 & 0 & 0 & 66 & 0 & 0 \\
\hline & Other Hymenoptera & 354 & 0 & 0 & 249 & 0 & 0 \\
\hline \multirow[t]{2}{*}{ Diptera } & Delia spp. & 534 & - & - & 1,645 & 15 & 0.91 \\
\hline & Other Diptera & 123 & - & - & 189 & 0 & 0 \\
\hline \multirow[t]{5}{*}{ Hemiptera } & Macrosteles quadrilineatus & 95 & 0 & 0 & 0 & 0 & 0 \\
\hline & Philaenus spumarius & 153 & 2 & 1.31 & 0 & 0 & 0 \\
\hline & Lygus lineolaris & 66 & 0 & 0 & 60 & 0 & 0 \\
\hline & Empoasca fabae & 896 & 13 & 1.45 & 1,531 & 8 & 0.52 \\
\hline & Paraphlepsius spp. & 393 & 27 & 6.87 & 237 & 1 & 0.42 \\
\hline
\end{tabular}

${ }^{\text {a }}$ Collected $=$ number of samples collected, Pos $=$ number $(n)$ or percentage $(\%)$ of positive samples, and - indicates that Diptera populations were monitored in both 2016 and 2017 but only tested for E. amylovora in 2017. 


\section{DISCUSSION}

Under our field conditions, flies visited flowers more frequently than bees and we did not detect E. amylovora from either group during bloom. In 2018, the overall prevalence of infested

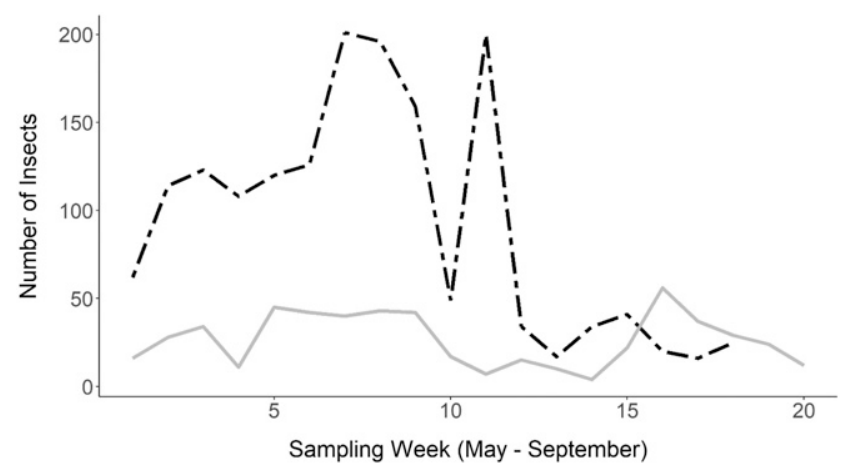

FIGURE 1

Population of Delia spp. captured on all yellow sticky cards in 2016 (gray solid line) and 2017 (block dashed line) in an experimental research orchard. The orchard, located in Geneva, NY, was planted in 2012 with Malus domestica 'Idared' on B.9 rootstock and was inoculated with Erwinia amylovora in 2015.

TABLE 3

Monthly breakdown of insects testing positive for the presence of Erwinia amylovora sampled from yellow sticky cards

\begin{tabular}{lcrrcc}
\hline Year & May & June & July & August & September \\
\hline 2016 & 0 & 8 & 18 & 9 & 7 \\
2017 & 4 & 17 & 2 & 1 & 0 \\
\hline
\end{tabular}

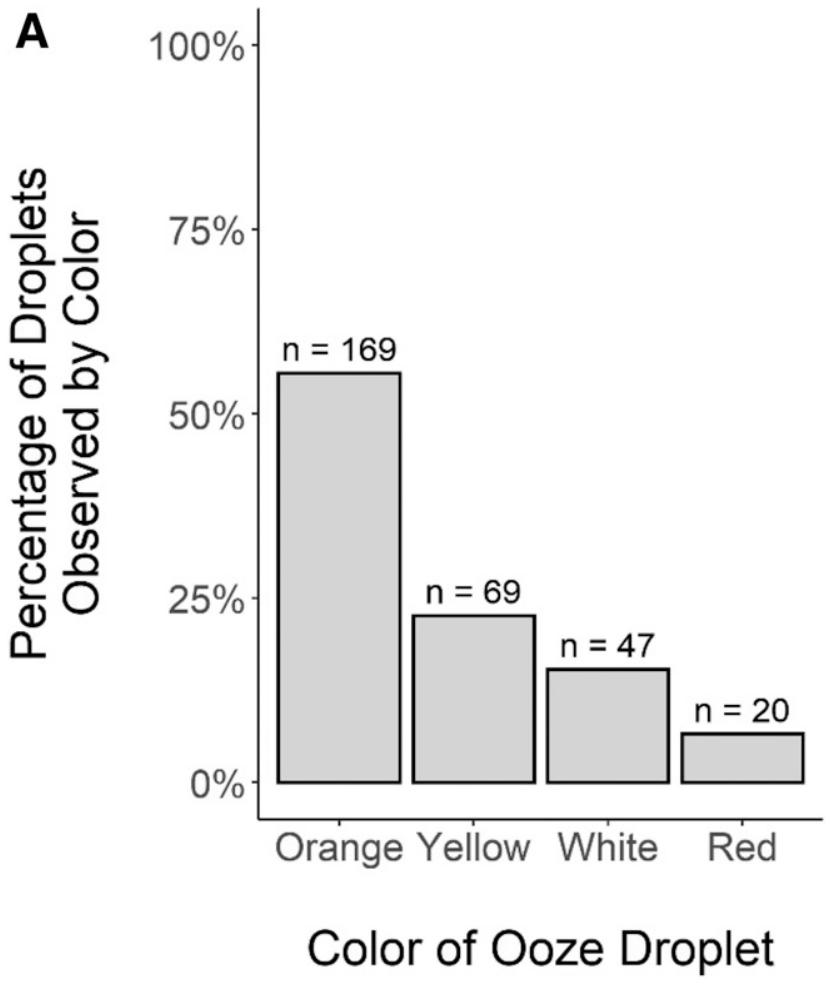

flowers was low and pollinating bees visited infested flowers at low frequencies; therefore, we were unable to establish a pattern of infested flower avoidance that was previously reported (Cellini et al. 2019). Bloom progressed rapidly in 2018 and it is likely that frequent E. amylovora acquisition from flowers depends on conditions that allow for longer bloom periods and steadier bacterial population growth on stigmas. When ooze was more prevalent in the summer, we detected E. amylovora in dipterans and hemipterans at low rates, and close to $70 \%$ of insects containing E. amylovora were collected in June and July in 2016 and 2017. Furthermore, we showed that flies feeding on ooze droplets in the field fed on ooze uninterrupted for greater than $6 \mathrm{~min}$ and $E$. amylovora persisted in or on flies for as long as 7 days after acquisition from ooze. Based on these observations, we posit that flies have a significant role in E. amylovora dissemination during the shoot blight phase of the disease cycle. These data should be interpreted with caution, because we only conducted experiments at one location and in one cultivar.

The absence of E. amylovora detection in pollinating bees was striking, because recent and historical research consistently implicated bees in blossom-to-blossom transmission (Cellini et al. 2019; Gossard and Walton 1922; Parker 1936). It is possible that bees in our study acquired E. amylovora but that titers were below the detection threshold of the 2016-to-2017 PCR assays, because we did not establish a detection threshold for this survey. Small titers deposited on flowers can multiply to high levels within a few days (Lindow and Suslow 2003); thus, bees carrying E. amylovora below our detectable levels could still generate significant spread. However, in our 2018 pollinator survey, we serially diluted and plated fresh samples to detect $E$. amylovora on insects and still failed to do so despite both a low detection threshold (200 CFU/ml) and concurrent detection on flowers. One study demonstrated that initial inoculums at or below $1 \times 10^{2} \mathrm{CFU} /$ flower rarely, if ever, lead to blossom blight

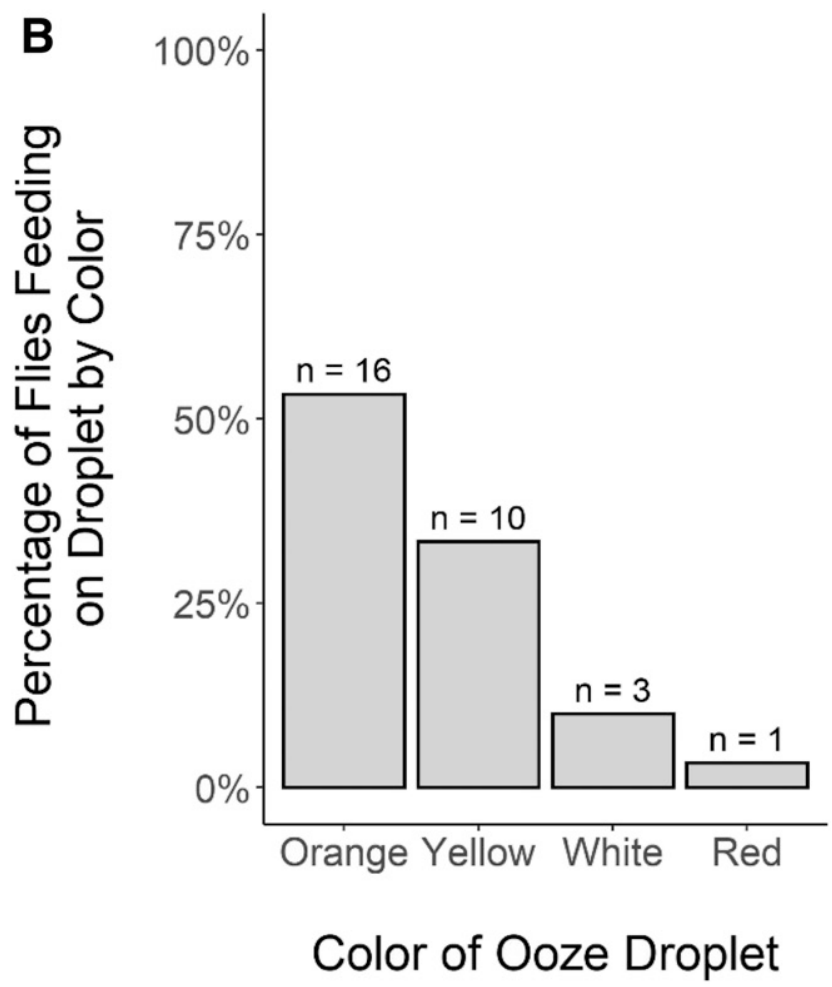

FIGURE 2

Percentage of A, Erwinia amylovora ooze droplets by color in an experimental orchard and B, visited by flies. There were no significant differences between observed frequency of droplet colors and frequency of droplet colors visited by flies $\left(\chi^{2}=2.5898, P=0.4503\right)$. 
in the field (Pusey and Smith 2008), suggesting that low bacterial loads carried by an individual bee may not be sufficient to cause blossom blight on its own. Of course, this does not rule bees out as disease disseminators because they have been shown to be effective transmitters under the right environmental conditions (Johnson et al. 1993), and because it does not account for many bees visiting and transmitting E. amylovora to a single flower. This possibility could be especially important in commercial
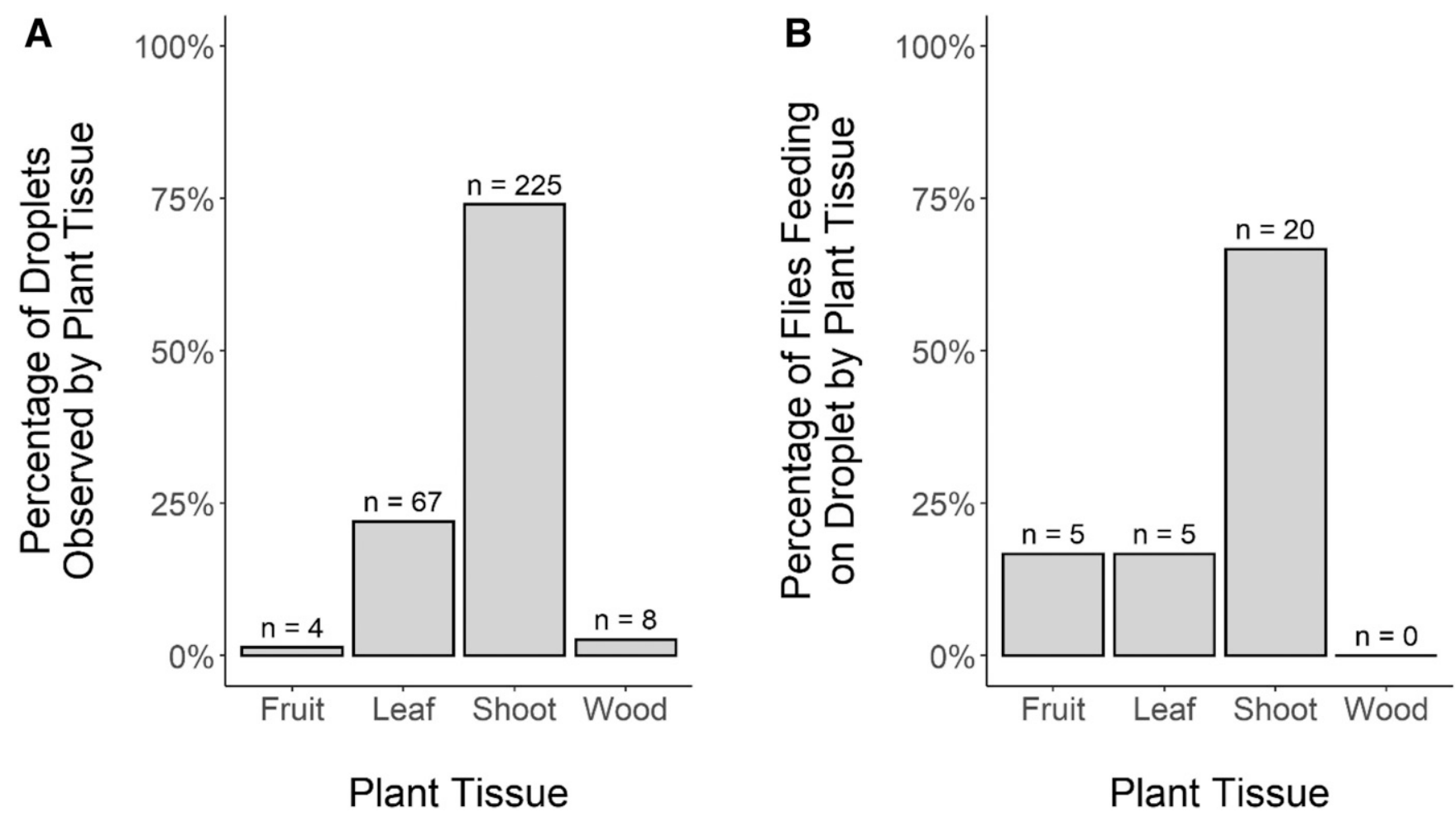

\section{FIGURE 3}

Percentage of Erwinia amylovora ooze droplets by plant tissue on Malus domestica 'Idared' on B.9 rootstock A, in an experimental orchard and $\mathbf{B}$, visited by flies. There was a significant difference between the frequency of droplet at each location and the frequency of droplet location visited by flies $\left(\chi^{2}=55.129, P=0.0005\right)$. Ooze droplets on wood consist of all droplets observed on lignified tissue.

TABLE 4

Summary of feeding behaviors for Dipterans observed on ooze in June 2018

\begin{tabular}{|c|c|c|c|c|c|c|c|}
\hline \multirow[b]{2}{*}{ Dipterans } & \multirow[b]{2}{*}{ Observed $(n)$} & \multicolumn{2}{|c|}{ Feeding times } & \multirow[b]{2}{*}{ Individuals captured $(n)$} & \multirow[b]{2}{*}{ Positive $(n)^{\mathrm{b}}$} & \multirow[b]{2}{*}{ Positive $(\%)^{\mathrm{b}}$} & \multirow[b]{2}{*}{ Mean days positive $(n)$} \\
\hline & & Range $(\min )^{\mathrm{a}}$ & Mean $(\min )^{\mathrm{a}}$ & & & & \\
\hline Delia spp. & 11 & $0: 12-5: 09$ & $2: 55$ & 7 & 4 & 57 & 3.0 \\
\hline Miscellaneous Diptera & 19 & $0: 02-6: 34$ & $2: 03$ & 9 & 6 & 67 & 4.5 \\
\hline Total & 30 & $0: 02-6: 34$ & $2: 22$ & 16 & 10 & 63 & 3.9 \\
\hline
\end{tabular}

a Times noted as minutes:seconds.

b Number and percentage of individuals positive for Erwinia amylovora.

\section{TABLE 5}

Summary of blossom visitation and behavior by insects during bloom 2018

\begin{tabular}{|c|c|c|c|c|c|c|c|c|c|}
\hline \multirow[b]{2}{*}{ Insects } & \multirow[b]{2}{*}{ Insects $^{\mathrm{a}}$} & \multicolumn{2}{|c|}{ Flowers visited $^{\mathrm{b}}$} & \multirow[b]{2}{*}{$\operatorname{Pos}(n)^{\mathrm{c}}$} & \multirow[b]{2}{*}{$\operatorname{Pos}(\%)^{\mathrm{c}}$} & \multirow[b]{2}{*}{ Fed $(\%)^{\mathrm{d}}$} & \multicolumn{2}{|c|}{ Approaching flower from } & \multirow[b]{2}{*}{ Time $(s)^{c}$} \\
\hline & & $N$ & Mean & & & & Side $(\%)$ & Top (\%) & \\
\hline Apis mellifera & 5 & 12 & 2.4 & 0 & 0 & 20 & 33.3 & 66.7 & $0: 10$ \\
\hline Small bee & 40 & 64 & 1.6 & 1 & 1.6 & 60 & 42.2 & 57.8 & $0: 31$ \\
\hline Medium bee & 22 & 42 & 1.9 & 3 & 7.1 & 60 & 28.6 & 71.4 & $0: 28$ \\
\hline Large bee & 10 & 15 & 1.5 & 0 & 0 & 79 & 26.7 & 73.3 & $0: 14$ \\
\hline Diptera & 90 & 128 & 1.4 & 8 & 6.3 & 75 & 67.5 & 32.5 & $0: 30$ \\
\hline Total & 167 & 261 & 1.6 & 12 & 4.6 & 69 & 50.6 & 49.4 & $0: 22$ \\
\hline
\end{tabular}

a Number of insects.

b Number and mean number (maximum $=3$ ) of flowers visited.

c Number and percentage of positive (Pos) flowers visited.

${ }^{d}$ Percentage of individuals that fed on nectar.

e Mean interaction time with flower. 
orchards that use pollination services, which results in hundreds of thousands of bees present in the orchard at one time (Johnson et al. 1993). In contrast, we found relatively few bees in our 2018 study and patchy E. amylovora infections, and it is possible that more bees would have led to a larger, more uniform outbreak.

Fire blight incidence in the research orchard was rare during bloom in 2018, which was likely due to a combination of low bloom density caused by tree die off and the late and rapid progression of bloom. Environmental conditions were conducive to E. amylovora development during bloom, with high humidity and warm temperatures (Steiner 1990). Bacterial populations in flowers increased as bloom progressed, with the highest populations being reached after $80 \%$ petal fall, when floral resources were scarce and pollinator foraging was low. Control flowers contained significantly higher bacterial populations than insectvisited flowers but this likely occurred because more infested control flowers (19 of 35) were collected later in bloom than infested, insect-visited flowers (1 of 12), and bacterial populations are generally at their highest later in the season (Thomson 1986). Thus, insect visitation decreased as pathogen populations peaked, which likely led to the lack of pathogen detection on pollinators when combined with the limitations discussed above.

Indeed, weather might also explain our lack of pathogen detection on pollinators in 2016 and 2017. Year 2016 was considered dry, with relatively little rain, low humidity, and cool temperatures, leading to relatively few symptomatic clusters even on infested trees (0 to 31\%) (Steiner 1990). In 2017, bloom

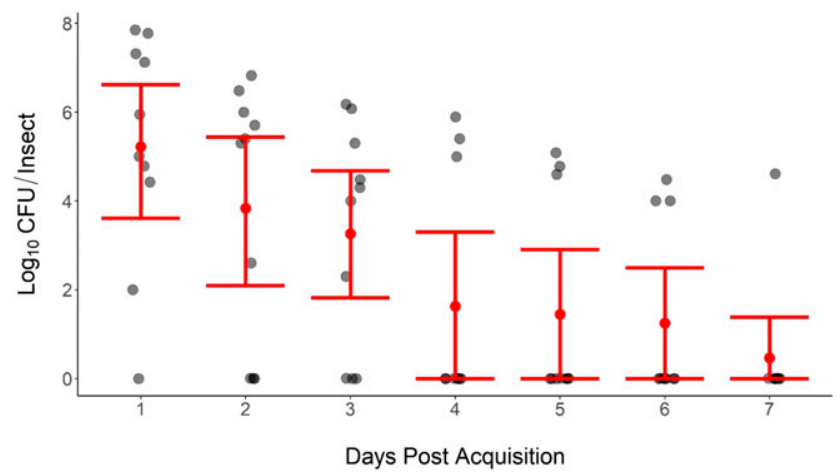

FIGURE 4

Persistence of Erwinia amylovora (mean $\log _{10}[\mathrm{CFU}+1]+95 \%$ confidence interval for each day) in 10 dipteran samples collected after feeding on ooze in the field and evaluated for $E$. amylovora daily for 7 days. Decline in mean $E$. amylovora population in flies approximated exponential decay. E. amylovora populations were measured by plating and populations below detectable levels were considered zeroes. Zeroes were incorporated into the calculation of the mean for each day. Black points represent CFU counts from individual flies. progressed rapidly following a cold spell that lasted approximately 6 days after the first king flowers opened. Temperatures during this spell were too cold for pollinator activity and the incidence of blighted clusters on individual trees was lower than in 2016 ( 0 to 20\%). Bloom time environmental conditions are likely to continue to become more unpredictable as the effects of climate change worsen (Wolfe et al. 2018), and the intersection of climate change and pollinator-driven spread of E. amylovora should be a major focus of future research.

The observed prevalence of flies on flowers accords with recent attention paid to flies as underappreciated pollinators (Raguso 2020). In a metaanalysis of farmland pollination, flies accounted for two-thirds of total pollinator abundance (Orford et al. 2015), underscoring significant interactions between flies and flowers in agroecosystems. Previous researchers observed several families of Diptera feeding on overwintering cankers and suggested that these flies are the primary disseminators of E. amylovora from cankers to blossoms (Parker 1936). We argue that new efforts should be made to understand the canker-to-blossom transmission mechanism and the broader role of flies in the dissemination of blossom blight (Slack et al. 2017). In our study, flies fed on nectar during $75 \%$ of visits but we did not detect $E$. amylovora on any of these samples. We believe that this result stems from the rarity and patchiness of blossom blight in the orchard in 2018. The role of flies in the spread of blossom blight requires further study, and will likely depend on the fly species, life history, and population size of the insect, and how these factors interact with the distribution and availability of active overwintering cankers across ecological scales (Orford et al. 2015; Raguso 2020).

Flies continue to be problematic following bloom. Overall detection of E. amylovora was low in 2016 and 2017, and we believe that we are underreporting the actual prevalence of positive insects in the field based on our 2018 observations. Our 2018 survey of bacterial persistence in live flies showed a mean retention of 4 days, indicating that 7-day intervals between sticky card collections may have been too long. It is also possible that sample desiccation on the yellow sticky cards led to degradation of E. amylovora in those samples, although this has not been a problem in related pathosystems (Bextine et al. 2005). Despite the low counts, some patterns were apparent. The rate of samples containing E. amylovora in June and July relative to the rest of the growing season suggests this that this 2-month window is when the potential for insect transmission in New York is at its highest. This window coincides with the highest prevalence of ooze in diseased orchards (Slack et al. 2017), making inoculum readily available to insects during this time. The population of Delia spp., the most prevalent fly in our orchard, peaked during these months, and flies were frequently observed visiting ooze during this time. We demonstrated that flies shed E. amylovora for several days after interacting with ooze, indicating that they can deliver bacteria to plant surfaces, after which E. amylovora can opportunistically colonize wounds or natural openings (Boucher

TABLE 6

Summary of positive flowers visited by insects and collected as controls ${ }^{\mathrm{a}}$

\begin{tabular}{|c|c|c|c|c|}
\hline \multirow[b]{2}{*}{ Parameters } & \multirow[b]{2}{*}{ Total $(n)^{\mathrm{b}}$} & \multicolumn{3}{|c|}{ Percentage of positive flowers on } \\
\hline & & Day 1 to 2 & Day 3 to 4 & Day 5 to 6 \\
\hline Insect visits & 261 & $0.97 \%$ ( 1 of 103$)$ & $7.94 \%(10$ of 126$)$ & $3.13 \%(1$ of 32$)$ \\
\hline Control samples ${ }^{\mathrm{c}}$ & 315 & $0.78 \%(1$ of 128$)$ & $12.40 \%(16$ of 129$)$ & $32.76 \%(19$ of 58$)$ \\
\hline
\end{tabular}


et al. 2019; Slack et al. 2017; Stahl and Luepschen 1977; Stewart and Leonard 1916).

Ooze droplet color did not differentially attract flies as was previously suggested (Slack et al. 2017), though additional attention to this question is necessary. We did identify a difference in observed droplet location in the field compared with droplet location visited by flies. Flies visited oozing fruit more frequently than the observed distribution of ooze on fruit. This may be mediated by unknown qualities associated with ooze or possibly by the odor profile of diseased fruit. Previous research hypothesized that fermenting odors brought on by E. amylovora infection may be attractive to flies (Thomas and Ark 1934). However, close to $70 \%$ of flies visited ooze on shoots, where it is most often located, suggesting that this is where acquisition is most likely to occur during the summer. Understanding the sensory mechanisms underlying how insects locate diseased tissue is a key aspect of transmission that remains unstudied.

The role of hemipterans in the spread of E. amylovora remains a question. Although field samples were occasionally positive in both survey years, we never observed hemipterans feeding on ooze and we do not know if positive individuals can successfully transmit bacteria. The count of positive hemipterans is likely underestimated for reasons described above and additional research is necessary to determine the transmission capacity of common hemipterans in apple orchards. Early researchers proposed that the feeding wounds created by hemipterans act as points of entry for bacteria delivered to plant surfaces by flies (Stahl and Luepschen 1977; Stewart and Leonard 1916). We propose that hemipteran feeding could release surface tension created by subdermal bacterial growth and exopolysaccharide production (Slack et al. 2017), allowing ooze to leak out of the resulting feeding wound. A similar phenomenon occurs in healthy trees damaged by hemipterans (Downes and Dahlem 1987). Moreover, flies have been observed feeding on the sap exuding from hemipteran feeding wounds (Downes and Dahlem 1987; Stewart and Leonard 1916), and Downes and Dahlem (1987) argued that honeydew was a source of concentrated sugar for flies prior to the evolution of flower nectar. If dipterans actively seek honeydew, then they might be predisposed to encounter hemipteran feeding wounds, which could then act as points of entry or inoculum sources.

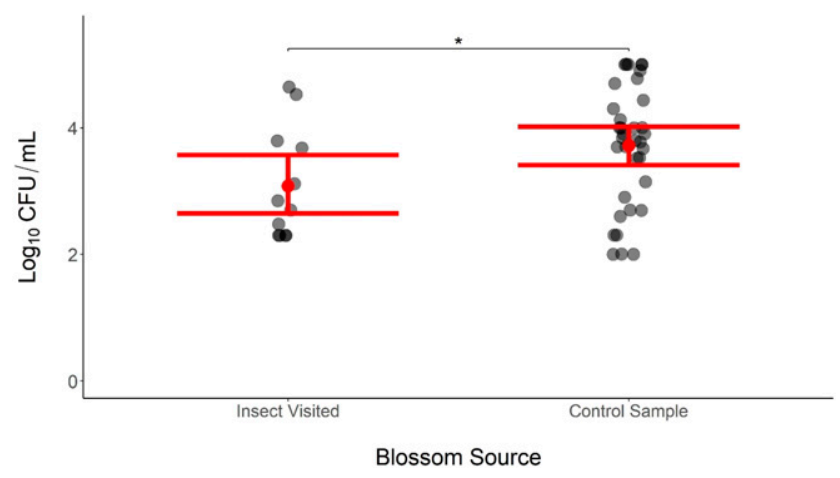

FIGURE 5

Erwinia amylovora (mean $\log _{10} \mathrm{CFU} / \mathrm{ml}+95 \%$ confidence interval) in control and insect-visited blossoms by sampling date. Figure only shows mean $\log _{10} \mathrm{CFU} / \mathrm{ml}$ for positive samples (insect visited: $n=12$; control: $n=35$ ), and all sampling dates were combined due to low $n$. Control samples are flowers that were collected immediately prior to insect visitation surveys to provide a snapshot of the size of bacterial populations in flowers containing $E$. amylovora. Asterisk $\left(^{*}\right)$ indicates $P<0.05$.
Collectively, this study provides a window into the ecological role of different insect guilds involved in the spread of $E$. amylovora in New York. The role of hemipterans in the disease cycle is still unclear, and interactions between hemipterans, dipterans, and E. amylovora should be studied in more depth. The role of pollinating bees has been documented extensively in previous work but the effect of climate-change-driven unpredictability of bloom-time conditions on pollinator-mediated spread requires further attention. Flies that visit flowers likely have an understudied role relative to the attention they have received, because they readily acquired $E$. amylovora from ooze in the early summer. Flies in the Muscidae and Anthomyiidae families preliminarily appear to be the most regular visitors to ooze, and their potential to shed bacteria after acquiring it from this source was demonstrated. Continued attention to interactions between insects and E. amylovora that we identify will advance our understanding of epidemiology and potentially help refine decision support tools in the future.

\section{ACKNOWLEDGMENTS}

We thank G. Sundin of Michigan State University for helpful discussions leading to the development of this study and E. Mudrak of the Cornell Statistical Consulting Unit for helpful comments on data analysis.

\section{LITERATURE CITED}

Agnello, A., Brown, B., Carroll, D., Cheng, L., Cox, K., Curtis, P., Helms, M., Kain, D., and Robinson, T. 2019. Cornell Pest Management Guidelines for Commercial Tree Fruit Production. Pesticide Management Education Program, Cornell University, Ithaca, NY, U.S.A.

Bextine, B., Blua, M., Harshman, D., and Miller, T. A. 2005. A SYBR Green based real-time polymerase chain reaction protocol and novel DNA extraction technique to detect Xylella fastidiosa in Homalodisca coagulata. J. Econ. Entomol. 98:667-672.

Boucher, M., Collins, R., Cox, K., and Loeb, G. 2019. Effects of exposure time and biological state on acquisition and accumulation of Erwinia amylovora by Drosophila melanogaster. Appl. Environ. Microbiol. 85: e00726-19.

Broadley, H. J., Boucher, M., Burand, J. P., and Elkinton, J. S. 2017. The phylogenetic relationship and cross-infection of nucleopolyhedroviruses between the invasive winter moth (Operophtera brumata) and its native congener, Bruce spanworm (O. bruceata). J. Invertebr. Pathol. 143:61-68.

Brooks, M. E., Kristensen, K., van Benthem, K. J., Magnusson, A., Berg, C. W., Nielsen, A., Skaug, H. J., Mächler, M., and Bolker, B. M. 2017. glmmTMB balances speed and flexibility among packages for zeroinflated generalized linear mixed modeling. R J. 9:378-400.

Carroll, J., Weigle, T., Agnello, A., Reissig, H., Cox, K., Breth, D., Robinson, T., Loeb, G., Wilcox, W., Eggleston, K., DeGaetano, A., Olmstead, D., Grant, J., Gibbons, J., and Petzoldt, C. 2017. NEWA (Network for Environment and Weather Applications) provides fruit IPM and production tools from 400 weather stations. N. Y. Fruit Q. 25:19-24.

Cellini, A., Giacomuzzi, V., Donati, I., Farneti, B., Rodriguez-Estrada, M. T., Savioli, S., Angeli, S., and Spinelli, F. 2019. Pathogen-induced changes in floral scent may increase honeybee-mediated dispersal of Erwinia amylovora. ISME J. 13:847-859.

Cieniewicz, E. J., Pethybridge, S. J., Loeb, G., Perry, K., and Fuchs, M. 2018. Insights into the ecology of grapevine red blotch virus in a diseased vineyard. Phytopathology 108:94-102.

Crosse, J. E. 1972. Leaf damage as a predisposing factor in the infection of apple shoots by Erwinia amylovora. Phytopathology 62:176-182.

Crosse, J. E., and Goodman, R. N. 1973. A selective medium for and a definitive colony characteristic of Erwinia amylovora. Phytopathology 63: 1425-1426.

Downes, W. L., and Dahlem, G. A. 1987. Keys to the evolution of Diptera: Role of Homoptera. Environ. Entomol. 16:847-854.

Farkas, A., Mihalik, E., Dorgai, L., and Buban, T. 2012. Floral traits affecting fire blight infection and management. Trees-Structure Funct. 26:47-66.

Gossard, H. A., and Walton, R. C. 1922. Dissemination of fire blight. Bull Ohio Agric. Exp. Stn. 537:83-126.

Johnson, K. B., Stockwell, V. O., Burgett, D. M., Sugar, D., and Loper, J. E. 1993. Dispersal of Erwinia amylovora and Pseudomonas fluorescens by honey bees from hives to apple and pear blossoms. Phytopathology 83:478-484. 
Keitt, G. W. 1941. Transmission of fire blight by bees and its relation to nectar concentration of apple and pear blossoms. J. Agric. Res. 62:745-753.

Leahy, K., Greene, D. W., Autio, W. R., and Norelli, J. L. 2006. Potato leafhoppers, fire blight and prohexadione-Ca: A look at their interaction under field conditions. Acta Hortic. 704:249-252.

Lenth, R., Buerkner, P., Herve, M., Love, J., Riebl, H., and Singmann, H. 2020. emmeans: Estimated marginal means, aka least-squares means. https://cran.r-project.org/web/packages/emmeans/index.html

Li, X.-W., Fail, J., Wang, P., Feng, J.-N., and Shelton, A. M. 2014. Performance of Arrhenotokous and Thelytokous Thrips tabaci (Thysanoptera: Thripidae) on onion and cabbage and its implications on evolution and pest management. J. Econ. Entomol. 107:1526-1534.

Lindow, S. E., and Suslow, T. V. 2003. Temporal dynamics of the biocontrol agent Pseudomonas fluorescens strain A506 in flowers in inoculated pear trees. Phytopathology 93:727-737.

McManus, P., and Jones, A. 1995. Genetic fingerprinting of Erwinia amylovora strains isolated from tree-fruit crops and Rubus spp. Phytopathology $85: 1547-1553$.

Miller, L. A., and McClanahan, R. J. 1960. Life history of the seed-corn maggot, Hylemya cilicrura (Rond.) and of H. liturata (Mg.) (Diptera: Anthomyiidae) in southwestern Ontario. Can. Entomol. 92:210-221.

Miller, T. D. 1972. Monitoring the epiphytic population of Erwinia amylovora on pear with a selective medium. Phytopathology 62:1175-1182.

Oh, C. S., and Beer, S. V. 2005. Molecular genetics of Erwinia amylovora involved in the development of fire blight. FEMS Microbiol. Lett. 253:185-192.

Ordax, M., Piquer-Salcedo, J. E., Santander, R. D., Sabater-Muñoz, B., Biosca, E. G., López, M. M., and Marco-Noales, E. 2015. Medfly Ceratitis capitata as potential vector for fire blight pathogen Erwinia amylovora: Survival and transmission. PLoS One 10:e0127560.

Orford, K. A., Vaughan, I. P., and Memmott, J. 2015. The forgotten flies: The importance of non-syrphid Diptera as pollinators. Proc. R. Soc. B 282: 20142934.

Parker, K. G. 1936. Fire blight: Overwintering, dissemination, and control of the pathogen. New York Agric. Exp. Stn. Mem. 193.

Pfeiffer, D. G., Killian, J. C., and Yoder, K. S. 1999. Clarifying the roles of white apple leafhopper and potato leafhopper (Homoptera: Cicadellidae) in fire blight transmission in apple. J. Entomol. Sci. 34:314-321.

Pierstorff, A. L., and Lamb, H. 1934. The honeybee in relation to the overwintering and primary spread of the fire blight organism. Phytopathology 24: 1347-1357.

Plurad, S. B., Goodman, R. N., and Enns, W. R. 1967. Factors influencing the efficacy of Aphis pomi as a potential vector for Erwinia amylovora. Phytopathology 57:1060-1063.

Pusey, P. L., and Smith, T. J. 2008. Relation of apple flower age to infection of hypanthium by Erwinia amylovora. Plant Dis. 92:137-142.
R Core Team. 2019. R: A Language and Environment for Statistical Computing. https://www.r-project.org/

Raguso, R. A. 2020. Don't forget the flies: Dipteran diversity and its consequences for floral ecology and evolution. Appl. Entomol. Zool. 55: $1-7$

Sebaihia, M., Bocsanczy, A. M., Biehl, B. S., Quail, M. A., Perna, N. T., Glasner, J. D., DeClerck, G. A., Cartinhour, S., Schneider, D. J., Bentley, S. D., Parkhill, J., and Beer, S. V. 2010. Complete genome sequence of the plant pathogen Erwinia amylovora strain ATCC 49946. J. Bacteriol. 192: 2020-2021.

Slack, S. M., Zeng, Q., Outwater, C. A., and Sundin, G. W. 2017. Microbiological examination of Erwinia amylovora exopolysaccharide ooze. Phytopathology 107:403-411.

Stahl, F. J., and Luepschen, N. S. 1977. Transmission of Erwinia amylovora to pear fruit by Lygus spp. Plant Dis. Rep. 61:936-939.

Steiner, P. W. 1990. Predicting canker, shoot and trauma blight phases of apple fire blight epidemics using the MARYBLYT model. Acta Hortic. 273:149-158.

Stewart, V. B. 1913. The importance of tarnished plant bug in the dissemination of fire blight in nursery stock. Phytopathology 3:273-277.

Stewart, V. B., and Leonard, M. D. 1916. Further studies in the role of insects in the dissemination of fire blight bacteria. Phytopathology 6:152-158.

Tancos, K. A., Villani, S., Kuehne, S., Borejsza-Wysocka, E., Breth, D. Carol, J., Aldwinckle, H. S., and Cox, K. D. 2016. Prevalence of streptomycin-resistant Erwinia amylovora in New York apple orchards. Plant Dis. 100:802-809.

Thomas, H. E., and Ark, P. A. 1934. Fire blight of pears and related plants. Calif. Agric. Exp. Stn. Bull. 586.

Thomson, S. V. 1986. The role of the stigma in fire blight infections. Phytopathology 76:476-482.

van der Zwet, T., and Keil, H. L. 1979. Fire Blight: A Bacterial Disease of Rosaceous Plants. Agriculture Handbook, no. 510. United States Department of Agriculture, Washington, D.C., U.S.A.

van der Zwet, T., Orolaza-Halbrendt, N., and Zeller, W. 2012a. The disease cycle of fire blight. Pages 155-182 in: Fire Blight: History, Biology, and Management. American Phytopathological Society, St. Paul, MN, U.S.A.

van der Zwet, T., Orolaza-Halbrendt, N., and Zeller, W. 2012b. Spread and current distribution of fire blight. Pages 15-36 in: Fire Blight: History, Biology, and Management. American Phytopathological Society, St. Paul, MN, U.S.A.

Wolfe, D. W., DeGaetano, A. T., Peck, G. M., Carey, M., Ziska, L. H., LeaCox, J., Kemanian, A. R., Hoffmann, M. P., and Hollinger, D. Y. 2018 Unique challenges and opportunities for northeastern US crop production in a changing climate. Clim. Change 146:231-245. 